\title{
Asymptomatic shedding and subsequent transmission of genital herpes simplex virus
}

\author{
S E BARTON,* J M DAVIS, $\uparrow$ V W MOSS,* A S TYMS, $\uparrow$ AND P E MUNDAY* \\ From the *Praed Street Clinic and the †Division of Virology, St Mary's Hospital and Medical School, \\ London
}

SUMMARY We report the transmission of genital herpes simplex virus (HSV) infection from an asymptomatic woman shedding virus from the cervix to two male sexual partners and further transmission from these two men while their infection was in the prodromal phase. The value of the restriction enzyme analysis of viral deoxyribonucleic acid (DNA) is presented. Guidelines regarding the management of patients who are found to be asymptomatic shedders of HSV are discussed.

\section{Introduetion}

Epidemiological studies of the transmission of genital herpes simplex virus (HSV) infection have been made more accurate by characterisation of viral deoxyribonucleic acid (DNA) by restriction endonuclease analysis. ${ }^{1-3} \mathrm{We}$ report the use of this method to study the transmission of genital HSV infection by an asymptomatic woman shedding virus from the cervix and to investigate viral isolates from subsequent recurrences of HSV infection.

\section{Case report}

A man aged 26 (case A) presented to the Praed Street Clinic complaining of penile ulceration of 24 hours' duration. He had had itching and redness of his penis and the systemic symptoms of headache, fever, and myalgia for five days. He had no history of any sexually transmitted disease (STD) or of oral HSV infection. A clinical diagnosis of genital herpes was made, which was confirmed by isolating the virus. The absence of complement fixing antibody to HSV showed that this was a primary episode. At the first visit, he reported that his elder brother (case B) had similar symptoms and also gave a sexual history (table) that suggested a common source of their problems.

We traced the female consort (case C), aged 33, who agreed to attend the clinic on the following day. She was symptomless and had no history of STD or of

Address for reprints: Dr S E Barton, Department of Gynaecology, Royal Northern Hospital, Holloway Road, London N7

This paper was presented at the spring meeting of the MSSVD held in Uppsala, Sweden, in May 1985.

Accepted for publication 28 June 1986.
HSV infection. On examination of her cervix, erythema and a mucopurulent discharge were visible, and colposcopic examination showed ulceration on the ectocervix. Routine tests for gonorrhoea, candidiasis, trichomoniasis, and chlamydial infection gave negative results, but HSV was isolated from the cervix. Complement fixing antibody to HSV was detected in her serum, with no signficant change in titre three weeks later, which suggested that this was a recurrent episode.

The next day the first patient's brother (case B) attended complaining of penile ulceration of three days' duration, which had been preceded by local irritation, malaise, and headache for four days. HSV was isolated, and antibody studies confirmed the diagnosis of primary genital HSV infection. All three patients gave negative serological test results for syphilis and had no concomitant genital infection. As the table shows, patients A and B had had sexual intercourse with other partners during the early phase of their infection while prodromal systemic symptoms and local redness and irritation were present, but before the onset of blistering and ulceration. Figure 1 shows the subsequent history of HSV infection in their sexual partners.

\section{TABLE History of sexual intercourse of seven patients}

\begin{tabular}{ll}
\hline Day & Event \\
\hline 0 & Case B had sexual intercourse with case C \\
7 & Case A had sexual intercourse with case C \\
12 & Case A had sexual intercourse with case E \\
13 & Case B had sexual intercourse with case D \\
14 & Case A had sexual intercourse with cases F and G \\
15 & Case A attended clinic \\
16 & Case C attended clinic \\
\hline
\end{tabular}




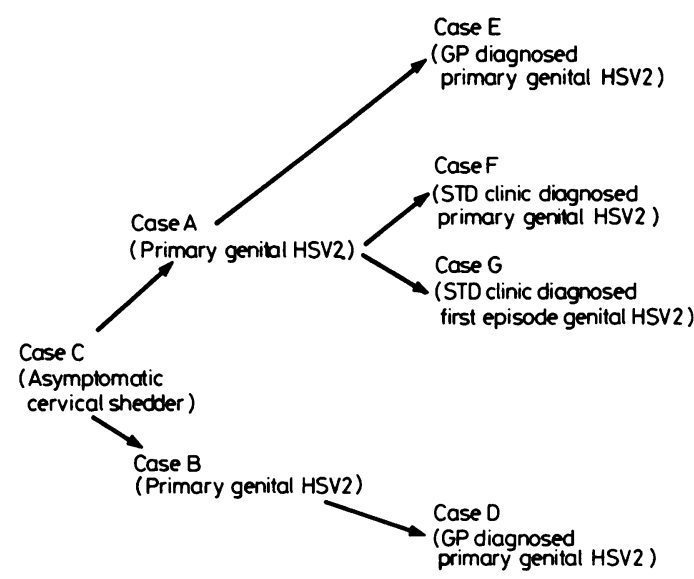

FIG 1 Diagram of transmission of herpes simplex virus type $2(H S V)$ ). (GP = general practitioner, $S T D=$ sexually transmitted diseases.)

We examined the DNA of the HSV isolates from patients $\mathbf{A}, \mathbf{B}$, and $\mathbf{C}$ using restriction endonuclease analysis as described previously. ${ }^{4}$ The viruses were identified as being type 2, and the electrophoretic profiles were identical when cleaved with the enzymes Bam H1, Xho 1 (fig 2), and Kpn 1 (results not shown).

The follow up of patients $A$ and $B$ provided interesting data. In the six months after diagnosis, $\mathbf{A}$ and $\mathbf{B}$ each had 10 recurrences: four of these began within five days of each other, a further two within seven days, and three more within 10 days. So far, two HSV 2 isolates from recurrent episodes in patient $B$ have been examined by restriction enzyme analysis with $\mathrm{Bam} \mathrm{H} 1$ (fig 2), Xho 1, and Kpn 1 (results not shown). DNA from both isolates was identical, in number and relative position of restriction enzyme cleavage sites, to DNA from the primary isolates of patients $B$ and $A$ and the cervical isolate from patient $\mathrm{C}$. We did not find DNA fragments differing in their electrophoretic mobility, which is a feature of recurrent isolates of HSV. ${ }^{145}$

\section{Discussion}

This case report raises several important points regarding genital HSV infection. Firstly, the value of contact tracing patient $\mathrm{C}$ and detecting the presence of asymptomatic cervical viral shedding was considerable. Mertz et al have argued that the identification and screening of such source contacts may reduce the transmission of the infection. ${ }^{6}$ Having been traced and identified as the source of the infection, however, this patient needed counselling on how to prevent further transmission of the disease. Our management began with an attempt to improve the awareness of her symptoms during an HSV recurrence in which lesions were not visible. In a previous study we had found that asymptomatic shedding from the genital tract was associated with tender inguinal lymphadenopathy, vaginal discharge, and dysuria. ${ }^{7}$ Patient $\mathrm{C}$ was encouraged to return for examination and to have tests for the presence of HSV whenever she wished. In the six months after diagnosis she returned 12 times: on four occasions she was found to have bacterial vaginosis, and on two candidiasis. HSV was not isolated from her urethra, cervix, or vulva at any of these visits. Advice was also given to the patient regarding the value of barrier contraception, as HSV cannot penetrate a sheath. ${ }^{8}$ Furthermore, the possibility of antiviral drug treatment was discussed, particularly the use of prophylactic continuous oral acyclovir, which has been shown to prevent symptomatic recurrences. ${ }^{910}$ No data are available on the effect of this treatment on genital asymptomatic shedding, but a study using prophylactic acyclovir in immunocompromised patients reported oral asymptomatic shedding during treatment. ${ }^{11}$ Patient $\mathrm{C}$ opted to wait until we had investigated her pattern of infectivity before any treatment was attempted.

Secondly, the transmission of genital HSV infection to four sexual contacts during the prodromal phase was an important feature in the transmission of the disease. Prevention of such transmission rests on improving health awareness and encouraging access to STD clinics, as well as on improving diagnostic techniques.

Thirdly, this case report offers an unusual opportunity to investigate the strain epidemiology and genome characteristics of a known virus during its transmission. Restriction enzyme analysis of viral DNA distinguishes unequivocally between HSV types 1 and 2 and characterises viruses within each serotype as being epidemiologically related or not by the presence or absence of restriction sites. ${ }^{12}$ The site of latency in the nervous system has been thought to be occupiable by only the single virus that caused the primary infection. ${ }^{13}$ There is now good evidence that mixed populations of HSV showing strain differences (variations in the number of restriction sites) exist within ganglionic cells in the nervous system. ${ }^{14}$ Size heterogeneity of restriction fragments due to reiteration of sequences in certain regions of the viral genome without a change in the number or relative position of restriction sites characterises HSV subpopulations in cell culture. ${ }^{15}$ These minor differences can distinguish between HSV type $1^{16}$ or type $2^{45}$ isolates from successive episodal attacks. Together these findings provide evidence for virus heterogeneity in the latent form of HSV. Reactivation of subpopulations of low virulence may interrupt the transmission of more pathogenic forms of HSV. Alternatively, virus populations in the latent form, which are homogeneous, might 


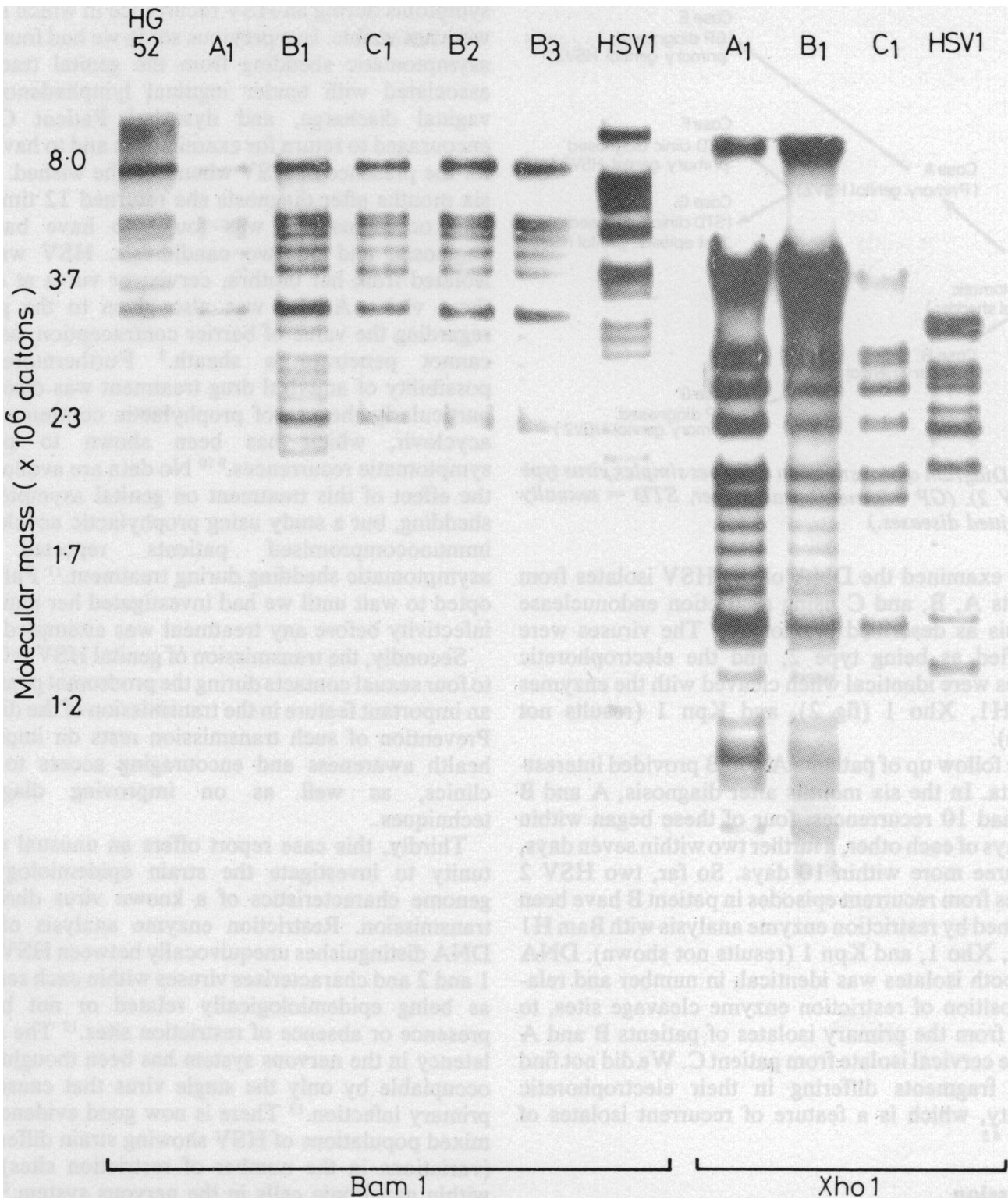

FIG 2 Electrophoretic profiles of DNA from type 2 reference virus (HG52), isolate from asymptomatic shedder (case $C$ ), primary isolates ( $A$ and $B$ ) from two brothers (cases $A$ and $B$ ), and recurrent isolates $\left(B_{2}\right.$ and $B_{3}$ ) from case $B$ after digestion with Bam H1; and profiles of DNA from viruses $A, B$, and $C_{1}$ and herpes simplex virus type 1 (HSV 1) after digestion with Xho 1.

be expected to maintain their inherent characteristics during reactivation and transmission.

The herpes simplex virus strain studied in this case report retained total identity by restriction enzyme analysis after transmission to two people, which resulted in concurrent infections, and during two episodes of reactivation in one patient. The efficiency of transmission of this virus seems to be high. The close temporal relation of the onset of recrudescence in the brothers would be unlikely if only exogenous factors triggered recurrences. Each patient has a different occupation and lifestyle, and therefore endogenous characteristics of the virus probably exerted an important effect on the timing of recurrences. A more frequent rate of recurrence for HSV, type 2 is well documented. ${ }^{17}$ If the characterisation of HSV by 
analysis of viral DNA, viral proteins, ${ }^{13}$ or other features of virus growth eventually provide markers of virulence, such information will be useful both for counselling patients about prognosis and for planning management.

In conclusion we have shown that, though early tracing of source contacts of patients with genital HSV is of value, it does not prevent the transmission of HSV infection in the early phase of the disease. To help reduce the spread of this disease we need improved health education, faster diagnostic techniques, and further research into the patterns of asymptomatic shedding of HSV and the relation of DNA restriction endonuclease profiles to recurrent disease patterns.

We thank the Joint Standing Research Committee at St Mary's Hospital, London W2, for its support. We also thank Helen Brown for her help in preparing the manuscript. The molecular weights for the HG52 DNA fragments, and the virus, were kindly supplied by Dr Andrew Davison, Institute of Virology, Glasgow.

\section{References}

1. Maitland NJ, Smith IW; Peutherer JF, Robertson DH, Jones $\mathrm{KW}$. Restriction endonuclease analysis of DNA from genital isolates of herpes simplex virus type 2. Infect Immun 1982;38:834-42.

2. Roizman B, Tognon M. Restriction enzyme analysis of herpesvirus DNA; stability of restriction endonuclease patterns. Lancet 1982; ii:677.

3. Barton SE, Munday PE, Davis JM, Tyms AS. Restriction enzyme analysis and herpes simplex infections. Lancet 1985;i:1448-9.

4. Davis JM, Jeffries DJ, Tyms AS, Walker D. Molecular biology in viral diagnosis: restriction enzyme analysis of viruses from recurrent genital herpes infections. Analyst 1985;110:605-9.
5. Schmidt OW, Fife KH, Corey L. Reinfection is an uncommon occurrence in patients with symptomatic recurrent genital herpes. J Infect Dis 1984;149:645-6.

6. Mertz GJ, Schmidt O, Jourden JL, et al. Frequency of acquisition of first episode genital infection with herpes simplex virus from symptomatic and asymptomatic source contacts. Sex Transm Dis 1985;12:33-9.

7. Barton SE, Wright JK, Link CM, Munday PE. Screening to detect asymptomatic shedding of herpes simplex virus in women with recurrent genital herpes. Genitourin Med 1986;62:181-5.

8. Conant MA, Spicer DW, Smith CD. Herpes simplex virus transmission: condom studies. Sex Transm Dis 1984;1:94-5.

9. Mindel A, Faherty A, Hindley D, et al. Prophylactic oral acyclovir in recurrent genital herpes. Lancet 1984;ii:57-9.

10. Strauss SE, Takiff HE, Seidlin M, et al. Suppression of frequently recurring genital herpes. N Engl J Med 1984;310:1545-50.

11. Shepp DH, Dandliker PS, Flournoy N, Meyers JD. Once-daily intravenous acyclovir for prophylaxis of herpes simplex virus reactivation after marrow transplantation. $J$ Antimicrob Chemother 1985;16:389-95.

12. Roizman B, Toigman M. Restriction endonuclease patterns of herpes simplex virus DNA: application to diagnosis and molecular epidemiology. In: Bachman PE, ed. New developments in diagnositc virology. Berlin: Springer-Verlag, 1983 (Curr Top Microbiol Immunol 104):273-86.

13. Lonsdale DM, Brown SM, Subak-Sharpe JH, Warren KG, Kowprowski $H$. The polypeptide and the DNA restriction enzyme profiles of spontaneous isolates of herpes simplex virus type 1 from explants of human trigeminal, superi or cervical and vagus ganglia. J Gen Virol 1979;43:151-71.

14. Lewis ME, Leung W-C, Jeffrey VM, Warren KG. Detection of multiple strains of latent herpes simplex virus type 1 within individual human hosts. J Virol 1984;52:300-5.

15. Davison A, Wilkie NM. Nucleotide sequences of the joint between $\mathrm{L}$ and $\mathrm{S}$ segment of herpes simplex virus type 1 and $2 . J$ Gen Virol 1981;55:315-31.

16. Toigman M, Bartoletti A, Constanzo F, Mannis-Palenzoma A, Cassal E. Bam H1 characterization of 15 HSV-DNAs isolated from recrudescent lesions of three individuals. Microbiologica 1984;7:85-90.

17. Reeves WC, Corey L, Adams HG, Vontver LA, Holmes KK. Risk of recurrence after first episode of genital herpes. $N$ Engl J Med 1981;305:315-9. 